\title{
MICROSATELLITE MARKER BASED HYBRIDITY ASSESSMENT FOR SALINITY TOLERANCE IN RICE
}

\author{
Short Communication
}

\author{
D. R. Gimhani ${ }^{1}$, N. S. Kottearachchi ${ }^{1}$ and W. L. G. Samarasinghe ${ }^{2}$
}

\begin{abstract}
Development salinity tolerant rice varieties have been a prioritized research area in rice breeding programs in Sri Lanka. Present study was initiated with the cross of At354, a salt tolerant parent and Bg352, a salt susceptible parent aiming at identifying salinity tolerant quantitative trait loci (QTL) in elite rice background. In rice, as getting true hybrids is a technical problem, $F_{1}$ progeny was assessed using microsatellite markers that are close proximity to Saltol QTL in chromosome 1. SSR Markers such as RM1287, RM493, RM10772, RM10852 and RM140 were polymorphic between parents. Six true hybrids were selected by polymorphic markers and subsequent generations were developed successfully by single seed descent method. This study explains the feasibility of utilizing microsatellite markers for verification of hybridity, surveying of polymorphic markers in chromosome 1 of At354 and Bg352 and progress towards Recombinant Inbred Line population development.
\end{abstract}

Keywords: Hybridity assessment, Microsatellite markers, Rice, Salinity tolerance

\section{INTRODUCTION}

Salinity is the second most widespread soil problem in rice growing countries next to drought (Gregorio et al., 1997). The productivity of most paddy growing lands in Sri Lanka also declines every year due to soil salinity, which arises due to the introgression of seawater during high tide and the rising of shallow saline ground water particularly during the dry season. This condition has aggregated by the recent tsunami disaster experienced by Sri Lanka by leaving large extent of the croplands in coastal area without cultivation due to considerable increment of saline condition in soil. Therefore, development of salt tolerant varieties has been considered as one of the strategies to increase rice production in saline prone areas.

Salinity tolerance in rice is a quantitative trait which is governed by many genes (Islam, et al., 2011). Present study was initiated with the aim of identifying salinity tolerant quantitative trait loci (QTLs) in elite rice background under Sri Lankan environment. In view of this, development of mapping population for salt tolerance is a prerequisite because mapping populations provide an efficient means for identifying genes and studying their associations with various plant traits.

Generally in self-pollinating species, mapping population is generated by crossing homozygous parents which are distinctly different for the trait that is going to be assessed (Collard et al., 2005). However, in rice, getting true hybrids is a technical problem as self- fertilization may occur before out crossing preventing the transfer of desired traits in progenies. In addition, conventionally, the genetic purity of the rice hybrids is assessed by the Grow-Out Test based on specific morphological traits which is time consuming, restricted to a few characteristics, influenced by environmental condition, and inefficient. Consequently selected plants based on such traits may not be true hybrids and such inaccurate identification can adversely

\footnotetext{
I Department of Biotechnology, Faculty of Agriculture and Plantation Management, Wayamba Univesity of 96 Sri Lanka, Makandura, Gonawila (60170) (NWP), Sri Lanka.

2 Rice Research and Development Institute, Batalagoda, Ibbagamuwa, Sri Lanka.
} 
affect all stages of future breeding program (Tamilkumar et al., 2009). Therefore, present study reports the use of microsatellite markers for the precise assessment of hybridity in $F_{1}$ generation of At354 and Bg352 cross which is then subsequently advanced.

\section{MATERIALS AND METHODS}

\section{Experimental site and Plant material}

The study was conducted at the Department of Biotechnology, Faculty of Agriculture and Plantation Management, Wayamba University of Sri Lanka, Makandura, Gonawila in collaboration with the Rice Research and Development Institute (RRDI), Batalagoda and, the crosses were initiated in 2010. At354, derived from Pokkali and Bg94-1, was selected as the salt tolerant parent and $\mathrm{Bg} 352$, derived from $\mathrm{Bg} 380 / \mathrm{Bg} 367-4$ cross, was selected as the salinity susceptible parent.

\section{Hybridization and development of mapping population}

$\mathrm{F}_{1}$ seeds produced from $\mathrm{At} 354$ and $\mathrm{Bg} 352$ cross, treated with the fungicide were established in the nursery. Well grown $F_{1}$ seedlings were selected and they were assessed by microsatellite markers that were polymorphic between parents. Selected true $\mathrm{F}_{1}$ hybrids were advanced to subsequent generations through inbreeding towards recombinant inbred line population (RILs) by single seed descent method (SSD).

\section{DNA extraction}

Genomic DNA was extracted from putative $F_{1}$ individuals and two parents according to the method described in http://rgp.dna.affrc.go.jp/ rgp/protocols/QTL.pdf. The leaf pieces were homogenized with $300 \mu 1$ of DNA extraction buffer (1 M KCl, 1 M Tris HCl, 0.5 M EDTA). Homogenized mixtures were incubated at $70^{\circ} \mathrm{C}$ for $20 \mathrm{~min}$. Extracts were centrifuged at $13,000 \mathrm{rpm}$ for $15 \mathrm{~min}$ under room temperature. $100 \mu 1$ of ice cold iso-propanol was added into new eppendorf tubes, and the supernatant of the above centrifuged samples were transferred into them. Solutions were mixed gently. After mixing, tubes were kept at $4^{\circ} \mathrm{C}$ for $15-30 \mathrm{~min}$ and centrifuged at 13,000 rpm for 15 min under room temperature. DNA pellets were washed with $150 \mu 1$ of $70 \%$ ice cold ethanol by centrifuging at 13,000 rpm for $10 \mathrm{~min}$. Supernatants were removed and pellets were air dried and dissolved in $200 \mu 1$ of 1/10 TE buffer (10 mM Tris, $1 \mathrm{mM}$ EDTA).

\section{Microsatellite marker analysis}

According to the Thomson, et al., 2010, microsatellite markers located at the Saltol QTL in chromosome 1, were selected for the study (Table 01). The primer sequence information was obtained from the published sequence database (www.gramene.org).

PCR was conducted using 8 microsatellite markers with the $15 \mu 1$ PCR mixture consisted of $5 \mu 1$ of genomic DNA, $1.5 \mu 1$ of 10X PCR buffer, $1.2 \mu 1$ of dNTPs $(2.5 \mathrm{mM}$ of each dNTP), $0.8 \mu \mathrm{l}$ of primer mixture $(20 \mu \mathrm{M}$ of each Forward and Reverse primer) (Integrated DNA Technologies, USA) and $0.25 \mu 1$ of Taq DNA polymerase (5U/ $\mu 1$, Sigma, USA). Final volume of the mixture was adjusted to $15 \mu \mathrm{l}$ by adding sterile distilled water. PCR amplification was performed using thermal cycler, BIORAD (USA) and amplification profile consisted of initial denaturing at $95^{\circ} \mathrm{C}$ for 5 minutes followed by 35 cycles of 1 minute at $95^{\circ} \mathrm{C}, 30$ seconds at relevant annealing temperature (Table 01 ), 1 minute at $72^{\circ} \mathrm{C}$ and final extension cycle of 5 minutes at $72^{\circ} \mathrm{C}$. Amplified PCR products were analyzed using 3\% agarose gel.

\section{RESULTS AND DISCUSSION}

$\mathrm{F}_{2}$, backcross, and RILs are the three primary types of mapping populations used for molecular mapping (Collard et al., 2005). Unlike $\mathrm{F}_{2}$ or backcross populations RILs produce homozygous or 'true-breeding' lines 
that can be multiplied and reproduce without genetic change. In this attempt of producing RILs, as the parents of the cross, At354 and Bg352 exhibited comparatively similar visual appearance and both were in the category of $3 \frac{1}{2}$ months maturity time, molecular markers were used for screening of segregants. Similar studies have been conducted for the identification of rice hybrids and their respective parents, assessment of plant to plant variation within parental lines and testing the genetic purity of rice hybrids using molecular markers (Yashitola et al., 2002; Nandakumar et al., 2004; Yun et al., 2005; Sundaram et al., 2007).

According to the results of the hybridization, $119 \mathrm{~F}_{1}$ seeds resulted and only $14 \mathrm{~F}_{1}$ seeds successfully produced $\mathrm{F}_{1}$ seedlings exhibiting $11.7 \%$ of comparatively low seed viability. Five microsatellite markers of eight, viz., RM1287, RM493, RM10772, RM10852 and RM140 exhibited polymorphism between parents (Figure 01 and 02). These polymorphic markers were used to examine the hybridity of 14 well grown $F_{1}$ individuals. Accordingly, hybridity of $6 \mathrm{~F}_{1}$ individuals was confirmed proving their heterozygosity at the respective loci representing two specific alleles of both parents (Figure 02 ). Rest of the $8 \mathrm{~F}_{1}$ individuals were confirmed as off-types as they exhibited only one of the alleles of parents.

By selfing of selected 6 true hybrids, $350 \mathrm{~F}_{2}$ segregants were raised successfully followed by advancing of subsequent generations by SSD method as illustrated by Figure 03 . Assessment of homozygosity of $\mathrm{F}_{5}$ population indicated that all tested individuals (96 seedlings) were $100 \%$ homozygous which would be tally with the expected level of $92 \%$ homozygosity in Mendelian genetics.

\section{CONCLUSION}

In present study, hybridity of $6 \mathrm{~F}_{1}$ individuals derived from AT354/Bg352 cross was confirmed precisely with the RM1287, RM493, RM10772, RM10852 and RM140 microsatellite markers. By selfing of 6 true hybrids, $350 \quad \mathrm{~F}_{2}$ segregants were raised successfully followed by advancing of subsequent generations to $\mathrm{F}_{5}$ with the expected level of homozygosity. As the SSR markers used in this assessment are located in close proximity to Saltol QTL, they would possibly be useful for the identification of Saltol QTL in At354 and Bg352 cross.

Table 01: Selected rice microsatellite markers located at chromosome 1.

\begin{tabular}{|c|c|c|c|}
\hline Locus name & Primer sequence & SSR motif & $\begin{array}{c}\text { Annealing } \mathrm{T} \text {. } \\
\left(\mathbf{C}^{\mathrm{O}}\right)\end{array}$ \\
\hline RM562 & $\begin{array}{l}\text { CACAACCCACAAACAGCAAG } \\
\text { CTTCCCCCAAAGTTTTAGCC }\end{array}$ & $(\mathrm{AAG})_{13}$ & 53 \\
\hline RM493* & $\begin{array}{l}\text { TAGCTCCAACAGGATCGACC } \\
\text { GTACGTAAACGCGGAAGGTG }\end{array}$ & $(\mathrm{CTT})_{9}$ & 56 \\
\hline RM8115 & $\begin{array}{l}\text { TATATAGTAAATTTGTTTGGTGTAGG } \\
\text { ACAGATGGATATTATAAGAAGTAACA }\end{array}$ & $(\mathrm{TA})_{18}$ & 50 \\
\hline RM6711 & $\begin{array}{l}\text { TAGTGATAGGGGTGGTGTGG } \\
\text { TTACAAGCATGGGAGTTGGG }\end{array}$ & $(\mathrm{TAT})_{8}$ & 56 \\
\hline RM1287* & $\begin{array}{l}\text { GTGAAGAAAGCATGGTAAATG } \\
\text { CTCAGCTTGCTTGTGGTTAG }\end{array}$ & $(\mathrm{AG})_{17}$ & 53 \\
\hline RM10772* & $\begin{array}{l}\text { GCACACCATGCAAATCAATGC } \\
\text { CAGAAACCTCATCTCCACCTTCC }\end{array}$ & $(\mathrm{CTT})_{16}$ & 55 \\
\hline RM10852* & $\begin{array}{l}\text { GAATTTCTAGGCCATGAGAGC } \\
\text { AACGGAGGGAGTATATGTTAGCC }\end{array}$ & $(\mathrm{ATAG})_{5}$ & 58 \\
\hline $\mathrm{RM} 140 *$ & $\begin{array}{l}\text { TGCCTCTTCCCTGGCTCCCCTG } \\
\text { GGCATGCCGAATGAAATGCATG }\end{array}$ & $(\mathrm{CT})_{12}$ & 58 \\
\hline
\end{tabular}




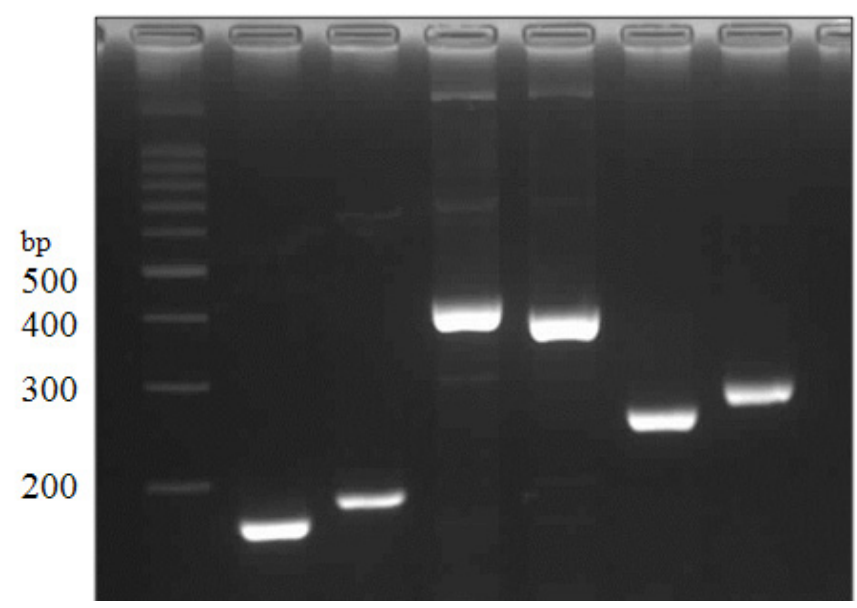

Figure 01: Polymorphism between parents, At354 and Bg352

Lane L- 100 bp DNA ladder, Lane 1,3 and 5- At354 amplified with RM10852, RM10772 and RM140 respectively, Lane 2,4 and 6- Bg352 amplified with RM10852, RM10772 and RM140 respectively

(a)

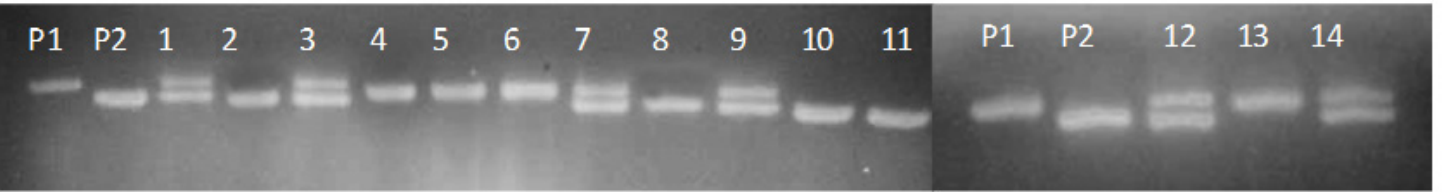

(b)

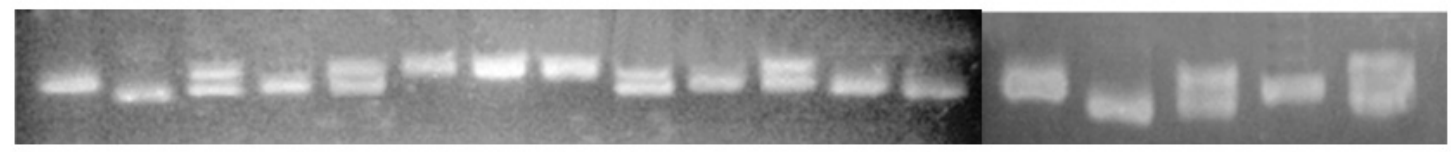

Figure 02: PCR profile generated with $F_{1}$ individuals from (a) RM1287, (b) RM493 SSR markers.

Lane P1- At354 parent, Lane P2-Bg352 parent, Lane 1-14- $\mathrm{F}_{1}$ individuals

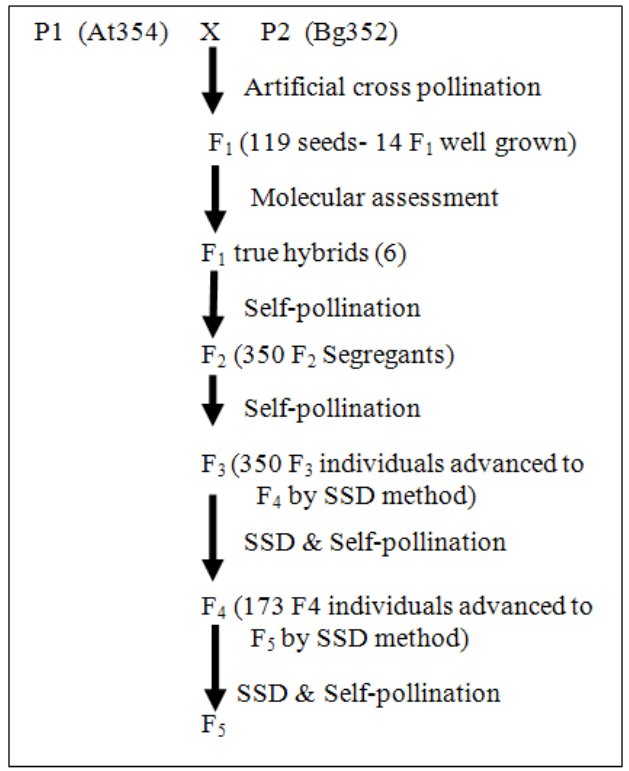

Figure 03: Schematic representation of the progress of developing mapping population 


\section{ACKNOWLEDGEMENTS}

The authors are thankful to the Research Grants received from the Wayamba University of Sri

Lanka (SRHDC/RP/01/10-05) and National Science Foundation (RG/2011/BT/02).

\section{REFERANCES}

Collard, B.C.Y., Jahufer, M.Z.Z., Brouwer, J.B. and Pang, E.C.K. (2005). An introduction to markers, quantitative trait loci (QTL) mapping and marker assisted selection for crop improvement: The basic concepts. Euphytica, 142, pp.169-196.

Gregorio, G.B., Senadhira, D. and Mendoza, R.D. (1997). Screening rice for salinity tolerance. IRRI Discussion paper Series No 22 International Rice Research Institute Los Baños Laguna Philippines

Islam, M.R., Salam, M.A., Hassan, L., Collard, B.C.Y., Singh,R.K. and Gregorio,G.B. (2011). QTL mapping for salt tolerance at seedling stage in rice. Emirates Journal of Food and Agriculture. 23 (2), pp.137-146.

Nandakumar, N., Singh, A.K., Sharma, R.K., Mohapatra, T., Prabhu, K.V. and Zaman, F.U. (2004). Molecular fingerprinting of hybrids and assessment of genetic purity of hybrid seeds in rice using microsatellite markers. Euphytica.136, pp.257-264.

Sundaram, R.M., Naveenkumar, B., Biradar, S.K., Balachandran, S.M. and Mishra, B. (2007). Identification of informative SSR markers capable of distinguishing hybrid rice parental lines and their utilization in seed purity assessment. Euphytica. 163, pp.215-224.

Tamilkumar, P., Jerlin, R., Senthil, N., Ganesan, K.N., Jeevan, R.J. and Raveendran, M. (2009). Fingerprinting of Rice Hybrids and their Parental Lines using Microsatellite Markers and their Utilization in Genetic Purity Assessment of Hybrid Rice. Research Journal of Seed Science, 2, pp.40-47.

Thomson, M.J., De Ocampo, M., Egdane, J., Rahman, M.A., Sajise , A.G., Adorada,D.L., Tumimbang-Raiz ,E.T., Blumwald, E., Seraj, Z.I., . Singh, R.K.,Gregorio,G.B and Ismail,A.M. (2010). Characterizing the Saltol Quantitative Trait Locus for Salinity Tolerance in Rice. Rice,3,pp. 148-160.

Yashitola, J., Thirumurugan, T., Sundaram, R.M., Naseerullah, M.K., Ramesh, M.S., Sarma, N.P. and. Sonti, R.V, (2002). Assessment of purity of rice hybrids using microsatellite and STS markers. Crop Sci., 42, pp.1369-1373.

Yun, X.Y., Zhan, Z., Ping, X.Y. and Ping, Y.L. (2005). Identification and purity test of super hybrid rice with SSR molecular markers. Rice Sci. 12,pp.7-12. 